\title{
Maternal-fetal bonding during the COVID-19 pandemic
}

\author{
Amanda Koire ${ }^{1,2}$, Leena Mittal ${ }^{1,2}$, Carmina Erdei ${ }^{2,3}$ and Cindy H. Liu' ${ }^{1,2,3^{*}}$ (1)
}

\begin{abstract}
Background: The pregnant population experienced unique COVID-19 physical and psychosocial stressors such as direct health concerns related to the virus and loss of access to resources since the COVID-19 emerged as a global pandemic in early 2020. Despite these COVID-19-related stress and concerns, the maternal experience of bonding with their unborn children has not been well studied. This work aimed to study the association between mental health history, current mental health symptoms, psychological factors, COVID-19-related worries, and self-reported maternal-fetal bonding of pregnant women.
\end{abstract}

Methods: This online, survey-based cross-sectional study focused on women pregnant during the pandemic and assessed 686 women using data collected from May 19, 2020 to October 3, 2020. Enrolled respondents completed assessments in which they self-reported maternal-fetal bonding, mental health symptomatology, psychological factors, and COVID-19-related worries regarding health, pregnancy, and resources.

Results: Depressive symptoms in pregnant women were associated with lower quality maternal-fetal bonding, while a higher level of anxiety was positively associated with bonding; however, past history of depression or generalized anxiety diagnosis did not appear to be as relevant as active symptomatology. Maternal resilience, but not distress tolerance, appeared to be a protective factor resulting in improved bonding. Higher levels of worry regarding impact of COVID-19 on health were significantly associated with improved bonding, while worries regarding the impact of COVID-19 on the pregnancy or resources were not significantly associated with bonding. The study also found associations between different sociodemographic variables and bonding, including a strong positive association between first time motherhood and bonding and a negative association between higher education and income and bonding.

Conclusions: This study was the first to report potential protective and risk factors to the maternal-fetal bonding process in women pregnant during the COVID-19 pandemic. Unique COVID-19 concerns exist; however, anxiety and COVID-19 concerns do not appear to undermine maternal-fetal bonding while active depressive symptomatology may negatively influence bonding; interventions increasing maternal resilience may be particularly valuable.

Keywords: Mental health, Pregnancy, Depression, Anxiety, Stress, Resilience, Attachment, Life events, Parenting, Distress

\section{Background}

The Coronavirus Disease 2019 (COVID-19) has presented unique stressors on the pregnant population since its emergence as a global pandemic in early 2020 [1].

\footnotetext{
*Correspondence: chliu@bwh.harvard.edu

${ }^{3}$ Department of Newborn Medicine, Brigham and Women's Hospital, Boston, MA, USA

Full list of author information is available at the end of the article
}

The direct physical effects of COVID-19 on pregnancy and on pregnant women are not well established. While the research on COVID-19 has now yielded results that are largely reassuring with regard to vertical transmission risk [2-4], recent studies point to increased morbidity and mortality of the virus in pregnant women as well as increased risk of preterm birth in infected women [5]. Beyond concerns related to the direct effects of the virus, alterations in prenatal care [6], various life stressors

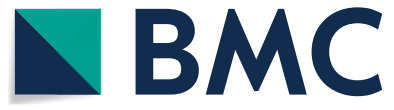
permits use, sharing, adaptation, distribution and reproduction in any medium or format, as long as you give appropriate credit to the original author(s) and the source, provide a link to the Creative Commons licence, and indicate if changes were made. The images or other third party material in this article are included in the article's Creative Commons licence, unless indicated otherwise in a credit line to the material. If material is not included in the article's Creative Commons licence and your intended use is not permitted by statutory regulation or exceeds the permitted use, you will need to obtain permission directly from the copyright holder. To view a copy of this licence, visit http://creativecommons.org/licenses/by/4.0/. The Creative Commons Public Domain Dedication waiver (http://creativeco mmons.org/publicdomain/zero/1.0/) applies to the data made available in this article, unless otherwise stated in a credit line to the data. 
including the loss of employment and other resources due to the pandemic $[7,8]$ are major psychosocial stressors to expectant families that can exacerbate stress and mental health concerns in the family [9-12]. Although there is published work on postpartum experiences of maternal bonding during the pandemic [13-16], the maternal experience of bonding with their unborn children is limited despite COVID-19-related emotional experiences [17].

Maternal-fetal bonding, the process of forming a relationship and an emotional connection to the fetus [18, 19], is an important first step in the process of bonding between mothers and children. Choosing a name, envisioning the baby's future, and describing the baby's 'personality' based on fetal movement patterns could all be thought of as part of this transition, in addition to tangible and perceptual experiences like listening to the heartbeat on a Doppler fetal monitor and visualizing the baby on the ultrasound $[20,21]$. Maternal-fetal bonding has been shown to predict attention to prenatal care [22] and postpartum bonding [23-25], an important factor considered foundational for later family and developmental outcomes [26-29]. Yet, there are few studies examining the factors associated with maternal-fetal attachment itself. Under non-pandemic conditions, a first pregnancy [30], later gestational age [24], ultrasound visualization of the fetus [31], and better partner support [32] appear to promote maternal-fetal bonding, while higher maternal education levels [32], depressive symptoms [32, 33], and substance abuse history [30] are potential risks to successful bonding; the influence of anxiety on maternalfetal bonding has received mixed reports [19, 22, 34]. Individual characteristics such as psychological resilience or distress tolerance are thought to have a role on one's well-being during the COVID-19 pandemic [35-37] but have not been well-studied even under non-pandemic conditions [38]. Poor maternal mental health can lead to difficulties in this bonding process and existing evidence suggests that the rates of anxiety and depression among pregnant women have increased during the pandemic beyond an already high general prevalence [39].

This study aimed to examine the associations between mental health history, current mental health symptoms, maternal psychological factors, worries related to the COVID-19 pandemic, and self-reported maternal-fetal bonding in pregnant women.

\section{Methods}

\section{Study design}

This was an online, survey-based cross-sectional study focused on women pregnant during the pandemic and at the time of data collection. Details of the broader study design and methodology can be found elsewhere $[10,16]$.

\section{Study setting}

Recruitment and data collection took place online between May 19, 2020 and October 3, 2020; recruitment was national and utilized word of mouth, email list-serves, and social media.

\section{Participants}

Participant eligibility criteria were female gender, aged 18 years or older, living in the United States, at least 6 weeks pregnant at the time of enrollment and data collection.

\section{Ethics}

Prior to any data collection, those eligible and interested in participating were asked to review an overview of the study including procedures, risks, benefits, participant rights, and study team contact information. Those who remained interested in study participation were asked to provide informed written consent of the study. This was obtained by participants selecting the statement "I agree to participate in the study" at the end of the informed consent. No compensation was provided for enrollment in or completion of the study. Participation was self-selecting and opt-in, and participants were able to withdraw their participation at any time.

All procedures were approved by the Mass General Brigham Institutional Review Board.

\section{Data collection}

Study participation constituted enrolled respondents participating in a 30-to-45-min survey administered online through REDCAP about pregnancy, experiences related to COVID-19, and psychological well-being as part of the PEACE (Perinatal Experiences and COVID19 Effects) 2020 Study. Participants completed the survey on average 121 days after March 13, 2020, at which the pandemic was declared a national emergency in the United States. Data quality was ensured by embedding various human verification steps such as reCAPTCHA as well as number counting tasks, and attention checks, including three multiple choice questions with the correct answer being purposely against common sense that required close reading comprehension of the prompt, in addition to inspections to assess for any response irregularities among various measures. These checks were designed to ensure that answer choices throughout the study were not made at random or insincere.

\section{Bias}

Attempts to address potential bias introduced by a selfselecting patient sample included lowering barriers to 
participation to encourage as widespread and representative enrollment as possible. In the United States, $85 \%$ of women own a smartphone, and over $91 \%$ of adults own either a computer or a smartphone [40,41]. By utilizing an online rather than clinical site-based enrollment approach and by using a variety of different online forums to reach potential participants, we removed potential obstacles to participation such as disparate access to transportation and medical care. The survey was designed such that respondents could complete the study over multiple sittings to further improve ease of participation and to enable those with more time-consuming work or home responsibilities to participate.

\section{Study size}

The study size was determined by the number of responses to the online survey during the study period. Data from all participants meeting eligibility requirements, with survey responses passing data quality standards and complete responses to all variables were used in the analysis $(N=686)$.

\section{Data sources}

All data for the variables used in this analysis were derived from the PEACE (Perinatal Experiences and COVID-19 Effects) 2020 Study as detailed above. This dataset is proprietary but can be made available upon reasonable request to the lead author.

\section{Study variables \\ Predictors}

COVID-19-related health worries This factor was calculated as a sum score of four items from the Coronavirus Health Impact Survey (CRISIS) that were designed to evaluate an individual's concern about COVID-19 directly affecting the health of oneself, family, and friends [42] through infection or through an influence on physical or mental health. Cronbach's $\alpha$ for measure items indicated good reliability $(\alpha=0.875)$.

COVID-19-related pregnancy worries COVID-19-related pregnancy worries, an 8-item measure developed for this study, evaluated worries specific to pregnancy during the COVID-19 pandemic. Participants indicated their level of concern about the potential impact of COVID-19 on their pregnancy, including concerns related to vertical transmission, prenatal care, and birth partner restrictions. The measure also incorporated their self-reported stress about visiting the hospital due to the COVID-19 pandemic. Cronbach's alpha indicated good reliability $(\alpha=0.810)$.
COVID-19-related resource worries COVID-19-related resource worries, a 6-item measure [43], evaluated the intensity of worries specific to accessing general resources during the COVID-19 pandemic. Participants indicated their level of concern about topics such as obtaining groceries, accessing healthcare, affording rent and basic necessities, and maintaining employment during the pandemic. Cronbach's alpha indicated good reliability $(\alpha=0.744)$.

Resilience The 10-item Connor-Davidson Resilience Scale [44] was used to measure participants' psychological resilience by assessing self-reported ability to cope with adverse experiences over the past month. Examples of items on the measure include "I am able to adapt when changes occur," "Having to cope with stress can make me stronger," and "I think of myself as a strong person when dealing with life's challenges and difficulties." Higher scores indicate higher resilience.

Distress tolerance The 15-item Distress Tolerance Scale [45] was used to measure participants' distress tolerance. Examples of items on the measure include "I'll do anything to avoid feeling distressed or upset" and "I feel ashamed of myself when I feel distressed or upset." Higher scores indicate greater distress tolerance.

Life events The Life Events measure inquired about participant experience over the past 6 months with 13 events, using a binary 'yes' or 'no' response. Examples of items on the measure include job loss, deployment, divorce, jail time, and homelessness [46].

Depression symptoms The Center for Epidemiologic Studies-Depression (CES-D)'s 20- item self-report measure was used to evaluate the severity of depression in participants [47]. When summed, total scores range from 0 to 60 and higher scores indicate more depressive symptoms.

Anxiety symptoms The Generalized Anxiety Disorder Scale (GAD-7 [48]) was used to evaluate current anxiety symptoms in participants. This 7-item scale assesses the frequency of anxiety symptoms experienced in the past two weeks using participant self-report. When summed, total scores range from 0 to 21 and higher scores indicate higher anxiety levels.

\section{Outcomes}

Maternal-fetal bonding To assess maternal-fetal bonding, we used the Maternal Antenatal Attachment Scale 
(MAAS [49]). This 18-item measure inquires about thoughts and feelings about the developing baby. Scores for all measures were summed; reverse scoring was performed for some items prior to summation as required by scale. Good reliability was verified by Cronbach's $\alpha$ for measure items $(\alpha=0.753)$.

\section{Potential confounders}

Pandemic duration The duration of the pandemic was defined as the period of time, in days, between when each respondent started the survey and the date when COVID-19 was declared as a pandemic (March 13, 2020).

Sociodemographic background Maternal Age, Maternal Race, Maternal Education level, Maternal Income, Gestational age of the fetus, Past Psychiatric History of Major Depressive Disorder or Anxiety, and Nulliparity were also included in the analysis as covariates.

\section{Quantitative variables}

Probable clinical depression was defined as CES-D $\geq 16$, consistent with recommendations for a cutoff score [50], with probable clinical anxiety was defined as GAD-7 $\geq 10$, in keeping with the cutoff score for moderate anxiety recommended by developers of the measures [48]. 'High levels of worry' for individual items within variable measures were defined as a response of 'Worried' or 'Very Worried, corresponding to the two highest options on a 5 -point Likert scale. All other quantitative variables were handled as raw scores for all statistical analysis.

\section{Statistical methods}

Data were analyzed in SPSS version 24 using descriptive and inferential statistical methods including Student's t-test, Pearson's correlation coefficient, and multiple regression analysis. For all analyses, only pregnancies with complete data on all variables of interest for this study were included, such that the total sample size for all analyses is constant $(N=686)$. Multiple regression analysis was conducted with maternal-fetal bonding regressed on sociodemographic characteristics (Block 1), mental health history (Block 2), current mental health symptoms (Block 3), psychosocial factors (Block 4), and COVID-19-related worries (Block 5), such that the contributions of potential confounders of maternalfetal bonding were controlled via a blocked structure to the analysis. The variables were normally distributed and predictors indicated acceptable levels of collinearity $(\mathrm{VIF}<5)$. Sensitivity analyses were not performed. Two subgroups were examined in more detail: those reporting high levels of worries about COVID-19 influencing their mental or emotional health, and those reporting high levels of worry that COVID-19 will affect their ability to bond with their baby, with CES-D and GAD-7 scores compared to the remainder of the cohort in the former subgroup, and MAAS scores in the latter subgroup, and analyzed in both cases with Student's t-tests.

\section{Results}

Table 1 presents the descriptive characteristics of our sample. The mean age of the sample was 33.1 years, older than the U.S. population average of 27 years [51]. In general, the sample comprised of White and college educated women. Among the respondents, $42 \%$ reported a household income of over $\$ 150,000$ per year and would thus be considered to be in an 'upper middle class' or 'rich' social class [52]. Gestational age (GA) was 28.4 weeks on average, and this was the first pregnancy for $53.1 \%$ of women

Table 1 Demographic characteristics from Wave I of the PEACE Study, data collected between May 19 and October 3, 2020

\begin{tabular}{|c|c|}
\hline Predictors & Means (Range) or \% \\
\hline Maternal age (years) & $33.1(22.3-46.3)$ \\
\hline Gestational age of fetus (weeks) & $28.4(7-41)$ \\
\hline \multicolumn{2}{|l|}{ Maternal race } \\
\hline White & $92.1 \%$ \\
\hline Black or African American & $1.0 \%$ \\
\hline Hispanic or Latino & $3.6 \%$ \\
\hline Asian and Pacific Islander & $3.2 \%$ \\
\hline Other & $0.0 \%$ \\
\hline \multicolumn{2}{|l|}{ Education } \\
\hline Less than college & $8.0 \%$ \\
\hline College & $31.8 \%$ \\
\hline Masters & $41.4 \%$ \\
\hline Doctorate & $18.8 \%$ \\
\hline \multicolumn{2}{|l|}{ Income } \\
\hline$<\$ 74,999$ & $13.8 \%$ \\
\hline$\$ 75,000-149,999$ & $44.6 \%$ \\
\hline$\$ 150,000-224,999$ & $25.5 \%$ \\
\hline$>\$ 225,000$ & $16.0 \%$ \\
\hline \multicolumn{2}{|l|}{ Prior Depression Diagnosis } \\
\hline No & $82.2 \%$ \\
\hline Yes & $17.8 \%$ \\
\hline \multicolumn{2}{|l|}{ Prior Anxiety Diagnosis } \\
\hline No & $73.0 \%$ \\
\hline Yes & $27.0 \%$ \\
\hline \multicolumn{2}{|l|}{ First pregnancy } \\
\hline No & $53.1 \%$ \\
\hline Yes & $46.9 \%$ \\
\hline Pandemic duration (days) & $121.2(69-201)$ \\
\hline
\end{tabular}

$N=686$ 
in this study, compared to an approximately $38 \%$ rate of first time live birth for women in the United States [51]. Approximately $17.8 \%$ of patients had a prior diagnosis of Depression while $27.0 \%$ had a prior diagnosis of Generalized Anxiety Disorder.

The mean scores for depression and anxiety symptoms assessed from standardized measures (CESD, GAD-7) are shown in Table 2. We observed a mean score of $14.31(\mathrm{SD}=9.04)$ on the CES-D and a mean score of 6.34 $(\mathrm{SD}=4.97)$ on the GAD-7 (probable clinical depression and anxiety is indicated with CES-D $\geq 16$ and GAD-7 $\geq 10$, respectively). The mean score of 14.31 on the CES-D corresponds to participants reporting that they have experienced the majority of response items for 1-4 days over the past week, with each item representing a depressive symptom. A mean score of 6.34 on the GAD-7 may be conceptualized as representing a response of 'several days' over the past two weeks for most items relating to anxiety symptom frequency, or 'nearly every day' for several items. Using the aforementioned binary cutoffs, 37.2\% of respondents reported symptom levels indicating probable clinical depression and $24.2 \%$ reported symptom levels indicating probable clinical anxiety. These states were highly comorbid, with $83.1 \%$ of women with probable clinical anxiety also experiencing probable clinical depression and $54.1 \%$ of women with probable clinical depression testing above the binary threshold for anxiety as well. Among our sample, $71.4 \%$ of women with probable clinical depression had no prior history of diagnosed depression, while $54.8 \%$ of women with probable clinical anxiety had no prior history of diagnosed anxiety.

Table 2 Maternal mental health, COVID-related concerns, and maternal experiences from Wave I of the PEACE Study, data collected between May 19 and October 3, 2020

\begin{tabular}{ll}
\hline Target Variables & Means (SD) \\
\hline $\begin{array}{l}\text { Mental health symptoms } \\
\text { Depression (CES-D) }\end{array}$ & $14.31(9.04)$ \\
$\quad$ Generalized anxiety (GAD-7) & $6.34(4.97)$ \\
Psychosocial factors & \\
$\quad$ Life Events & $1.35(1.33)$ \\
Resilience (CD-RISC) & $27.44(6.13)$ \\
Distress Tolerance (DTS) & $53.68(11.99)$ \\
COVID-19-related worries & \\
$\quad$ Health & $12.02(3.70)$ \\
Pregnancy & $20.15(6.42)$ \\
Access to resources & $11.48(4.24)$ \\
Maternal-fetal bonding & \\
Attachment (MAAS) & $71.82(7.29)$ \\
\hline N=686
\end{tabular}

The mean number of potentially distressing life events was $1.35(\mathrm{SD}=1.33)$, with the three most commonly experienced life events being 'I argued with my husband or partner more than usual,' 'My husband, partner, or I had a cut in work hours or pay', and 'A close family member was very sick and had to go to the hospital.' The average score for Resilience was 27.44 $(\mathrm{SD}=6.13)$, and for Distress Tolerance was $53.68 \quad(\mathrm{SD}=11.99)$. The mean scores for COVID-19-related worries were $12.02(\mathrm{SD}=3.70)$ for health worries, $20.15(\mathrm{SD}=6.42)$ for worries regarding impact on pregnancy, and 11.48 $(\mathrm{SD}=4.24)$ for worries regarding access to resources. Finally, participants had an average sum $71.82(\mathrm{SD}=7.29)$ out of a total possible score of 90 on the MAAS; a sum of 71 or below, corresponding to less than $80 \%$ the maximum MAAS, may be interpreted to represent low antenatal bonding [53]. The responses for COVID-19-related worries were further examined in Table 3, with a response of 'Worried' or 'Very Worried' being considered to represent high levels of concern. More than two-thirds of women reported high levels of stress about going to the hospital, and over half were highly worried about their physical health being affected by COVID-19. In contrast, high levels of concern about being able to obtain testing, hospital access, and treatment for COVID-19 were relatively uncommon. Amongst pregnancy-specific worries, the most common was that the birth partner or support person would not be able to be present during labor and delivery, with $44.2 \%$ of women expressing high levels of worry. Also frequent were high levels of worry about transmitting COVID-19 to the baby during breastfeeding or caretaking, which affected $33.7 \%$ of the cohort, and worries about contracting COVID-19 during labor and delivery, which affected $29.2 \%$. Although scientific knowledge about the risk of transmitting COVID-19 from mother to baby increased over time during the pandemic, there was no correlated decrease in these worries over time $(p=0.701)$.

Overall, women were more likely to be concerned about their mental and emotional health than about contracting COVID-19 itself. High levels of worries about COVID-19 influencing their mental or emotional health were experienced by $24.9 \%$ of women. This subset of women also had significantly higher CES-D scores (16.5 vs. 13.6, $p<0.0001)$ and higher GAD-7 scores (7.7 vs. $5.9, \mathrm{p}<0.0001)$. High levels of worries on this single item response produced a positive predictive value of $48.0 \%$ for probable clinical depression (CES-D $\geq 16)$ and 35.7\% for probable clinical anxiety (GAD-7 $\geq 10)$. Given this study's particular interest in bonding, groups of higher and lower levels of worries were compared for the specific response item in the COVID-19 pregnancy-specific worries scale about COVID-19 affecting their ability to 
Table 3 Maternal COVID-19-related worries

\begin{tabular}{|c|c|c|}
\hline COVID-19 Health Worries & ‘Lower worry' & 'Higher worry' \\
\hline ... about being infected? & $84.5 \%$ & $15.5 \%$ \\
\hline ... about friends or family being infected? & $88.6 \%$ & $11.2 \%$ \\
\hline ... about your physical health being influenced by COVID-19? & $48.4 \%$ & $51.6 \%$ \\
\hline ... about your mental/emotional health being influenced by COVID-19? & $75.1 \%$ & $24.9 \%$ \\
\hline COVID-19 Resource Worries & ‘Lower worry’ & 'Higher worry' \\
\hline ...that I won't have enough groceries during city lockdowns/social distancing protocols & $93.7 \%$ & $6.3 \%$ \\
\hline ...that I will not be able to obtain a COVID-19 test if I become sick & $96.2 \%$ & $3.8 \%$ \\
\hline ...that I will not be able to receive treatment for COVID-19 if I contract it & $94.2 \%$ & $5.8 \%$ \\
\hline ...about keeping in touch with loved ones during social distancing protocols & $75.5 \%$ & $24.5 \%$ \\
\hline ...about maintaining employment during the subsequent economic downturn & $80.5 \%$ & $19.5 \%$ \\
\hline ...about having enough money to pay for rent and buy basic necessities & $89.1 \%$ & $10.9 \%$ \\
\hline COVID-19 Pregnancy-Specific Worries & 'Lower worry' & 'Higher worry' \\
\hline ...to hold, care for, and (breast) feed my baby because I fear I may transmit the virus to my baby & $66.3 \%$ & $33.7 \%$ \\
\hline $\begin{array}{l}. . . \text { might become very sick, and I won't have another trusted family member or friend to care for my baby if } \\
\text { that happens }\end{array}$ & $76.5 \%$ & $23.5 \%$ \\
\hline ...I don't have a way to get to the hospital if I/my baby becomes sick and I need to see a doctor & $97.4 \%$ & $2.6 \%$ \\
\hline ...that COVID-19 related stress will affect my ability to bond with my baby & $84.7 \%$ & $15.3 \%$ \\
\hline ...about contracting COVID-19 during labor and delivery & $70.8 \%$ & $29.2 \%$ \\
\hline ...that I am not receiving adequate prenatal care due to COVID-19 & $83.4 \%$ & $16.6 \%$ \\
\hline ...that my birth partner or support person may not be able to be with me during labor and delivery & $55.8 \%$ & $44.2 \%$ \\
\hline I feel more stressed about going to the hospital because of COVID-19. & $32.9 \%$ & $67.1 \%$ \\
\hline
\end{tabular}

$N=686$

bond with their unborn baby. While 15.3\% (105/686) of women reported high levels of worries about their bonding, there was no significant difference in MAAS scores between the higher and lower levels of worries groups (71.84 vs $71.80, p=0.959$ ).

Table 4 reports the multiple regression results. The change in $\mathrm{R}^{2}$ was found to be significant $(p<.001)$ for all blocks besides mental health history. GA $(\beta=0.114$, $p<0.01)$, first pregnancy $(\beta=.169, p<0.001)$ and mothers reporting being Hispanic/Latino $(\beta=0.082, p<0.05)$ appeared positively associated with bonding. Higher incomes $(\beta=-0.122, \mathrm{p}<0.05)$ and educational levels $(\beta=-0.217, \mathrm{p}<0.01)$ did not appear protective. After accounting for sociodemographic characteristics as well as the pandemic duration, history of a mental health diagnosis (depression or anxiety) did not exhibit any significant association with maternal-fetal bonding. However, with prior mental health history taken into account, higher levels of endorsed depression symptoms during pregnancy were associated with lower levels of maternalfetal bonding $(\beta=-0.297, p<0.001)$ and higher levels of anxiety symptoms with higher levels of maternal-fetal bonding $(\beta=0.140, p<0.05)$. When considering depressive and anxiety symptoms, higher levels of resilience were correlated with higher levels of maternal-fetal bonding $(\beta=.175, \mathrm{p}<0.001)$, while distress tolerance and disruptive life events were not significantly correlated. Lastly, reported worries about COVID-19 related health were showed to contribute to the model based on the control of sociodemographic characteristics, mental health history, mental health symptoms, and psychosocial factors. Higher levels of COVID-19-related health worries were associated with higher levels of maternalfetal bonding $(\beta=0.160, p<0.01)$, whereas higher levels of COVID-19-related resource worries demonstrated a trend toward lower levels of maternal-fetal bonding $(\beta=$ $-0.083, p<0.1)$ and pregnancy-specific COVID-19 worries were not significant $(\beta=0.063, \mathrm{p}=$ n.s. $)$. COVID19-related worries accounted for $18.5 \%$ of the model variance with regards to maternal-fetal bonding.

\section{Discussion}

This study aimed to examine the association between mental health history, current mental health symptoms, psychological factors, worries related to COVID-19, and the self-reported maternal-fetal bonding experiences of pregnant women during the COVID-19 pandemic. Identifying the risks and protective factors for maternal-fetal bonding during the COVID-19 pandemic can facilitate tailored counsel to patients and clinicians.

Those completing the study were predominantly White, well-educated, and financially secure women 
Table 4 Multiple regression predicting maternal-fetal bonding based on mental health history, symptoms, psychosocial factors, and COVID-19-related worries

\begin{tabular}{|c|c|c|c|}
\hline \multicolumn{4}{|l|}{ Total score } \\
\hline Blocks of variables entered in four steps & $\beta$ & $R^{2}$ & $\Delta R^{2}$ \\
\hline \multicolumn{2}{|l|}{ 1. Covariates } & 0.076 & $0.076^{* * *}$ \\
\hline Maternal age (years) & -0.051 & & \\
\hline Gestational age of fetus (weeks) & $0.114^{* *}$ & & \\
\hline \multicolumn{4}{|l|}{ Maternal race } \\
\hline \multicolumn{4}{|l|}{ (ref = White) } \\
\hline Black & 0.048 & & \\
\hline Hispanic & $0.082^{*}$ & & \\
\hline Asian & $-0.060^{\dagger}$ & & \\
\hline \multicolumn{4}{|l|}{ Maternal education } \\
\hline \multicolumn{4}{|l|}{$($ ref $=$ less than college $)$} \\
\hline College & $-0.193^{* *}$ & & \\
\hline Masters & $-0.238^{* *}$ & & \\
\hline Doctorate & $-0.217^{* *}$ & & \\
\hline \multicolumn{4}{|l|}{ Maternal income } \\
\hline \multicolumn{4}{|l|}{$(r e f=<\$ 74,999)$} \\
\hline$\$ 75,000-149,999$ & -0.068 & & \\
\hline$\$ 150,000-224,999$ & -0.057 & & \\
\hline$\geq \$ 225,000$ & $-0.122^{*}$ & & \\
\hline First pregnancy $(r e f=n o)$ & $0.169^{* * *}$ & & \\
\hline Pandemic duration & 0.009 & & \\
\hline 2. Mental Health History & & 0.077 & 0.003 \\
\hline Prior Depression Diagnosis (ref=no) & 0.053 & & \\
\hline $\begin{array}{l}\text { Prior Generalized Anxiety Diagnosis } \\
(\mathrm{ref}=\mathrm{no})\end{array}$ & -0.037 & & \\
\hline 3. Mental Health Symptoms & & 0.14 & $0.064^{* * *}$ \\
\hline Depression & $-0.297^{* * *}$ & & \\
\hline Generalized anxiety & $0.140^{*}$ & & \\
\hline 4. Psychosocial factors & & 0.164 & $0.028^{* * *}$ \\
\hline Life Events & 0.011 & & \\
\hline Resilience (CD-RISC) & $0.175^{* * *}$ & & \\
\hline Distress Tolerance (DTS) & 0.031 & & \\
\hline 5. COVID-19-Related Worries & & 0.185 & $0.024^{* * *}$ \\
\hline Health & $0.160^{* *}$ & & \\
\hline Pregnancy & 0.063 & & \\
\hline Access to resources & $-0.083^{\dagger}$ & & \\
\hline
\end{tabular}

$N=686,+p<0.1,{ }^{*} p<.05,{ }^{* *} p<.01,{ }^{* * *} p<.001$

in their early thirties experiencing their first pregnancies. When reflecting upon COVID-19-related worries, participants rarely expressed worries about their ability to obtain COVID-19 testing and treatment. However, the majority of women expressed high levels of worries about the risk posed to their personal health. Entering the hospital and the labor and delivery process were of particular concern as a source of potential exposure. Although preliminary evidence doesn't indicate vertical transmission is a significant risk [3, 54], mothers expressed no attenuation of these worries over time in the absence of population-based evidence.

A number of factors appear to be protective of maternal-fetal bonding including greater GA, first pregnancy, those who identify as Hispanic/Latino, and high resilience scores. Higher incomes and educational levels were associated with poorer bonding. These associations were largely consistent with what has been reported in the literature under non-pandemic conditions [24, 30, 32]. Depressive symptomatology during pregnancy was highly correlated to poorer bonding even after accounting for past psychiatric history. This is highly relevant and concerning given that well over a third of respondents reported scores consistent with a positive screen for probable clinical depression. Higher levels of anxiety symptoms, on the other hand, did not appear to undermine the maternal-fetal bond in the same way, consistent with what has been reported postpartum [25, 55], and on its own appeared to be a protective factor for bonding. Similarly, COVID-19-related worries about pregnancy and obtaining resources were not negatively associated with maternal-fetal bonding and in the case of COVID-19-related health worries appeared to be protective. Even selfreported worries specifically about maternal-fetal bonding did not appear to predict poorer bonding. High levels of anxiety could in fact reflect maternal attachment and care toward their pregnancy during an uncertain time; alternatively, anxiety may predispose pregnant women to feeling more protective toward their unborn child [19].

Of psychological factors assessed by this study, resilience appeared to be a meaningful protective factor for maternal-fetal bonding. Past research has demonstrated resilience as a protective factor against prenatal anxiety and depression both in non-pandemic [56] and pandemic conditions [57], but our results suggest that resilience is associated with bonding even after accounting for depression and anxiety levels. It may be the case that women with higher resilience are more likely to take a long-term perspective of the future amenable to picturing their developing fetus as a person, or believe in their ability to develop an emotional connection. Higher levels of resilience were protective even in those with higher levels of depression. In contrast, distress tolerance was not significant, suggesting that the ability to adapt and overcome long-term challenges may be more relevant than the ability to cope with acute frustrations. Therefore, resilience-focused interventions using cognitive-behavioral therapy (CBT), mindfulness training, or a combination of both may be of particular benefit to patients during the pandemic [58-60].

Notably, past psychiatric history was not associated with bonding. Considering most women reporting 
probable clinical depression or anxiety had no prior diagnoses of depression or anxiety, this suggests clinically relevant distress may be newly emerging in many pregnant women and all patients should be screened carefully. Those presenting to clinics with anxiety symptoms should also be screened for depression given the high degree of comorbidity and disparate potential impacts on maternal-fetal bonding and because prenatal anxiety is associated with later postpartum depression [61].

This study has some limitations presented by the voluntary and self-selecting nature of participant enrollment, which resulted in demographics that are highly weighted toward highly educated, higher income, White women. Minimal concern regarding resource acquisition may reflect the relative financial stability of most completing the survey. These factors all may limit the generalizability of the study findings, and in the future additional focus on racial/ethnic minority and disadvantaged groups will be needed. As well, it is possible that women with COVID-19-related worries were more interested in engaging with the study, which could result in an overinflation of estimates of worry/anxiety symptoms; similarly, those with very high levels of depressive symptoms impairing concentration and attention may have been screened out by quality control attention checks and thus be underrepresented. However, the design of the study may also allow it to be particularly well-poised to capture the group of women who are most likely to be presenting questions and concerns to their obstetricians at this time.

\section{Conclusions}

Based on these findings, we conclude that COVID19-related worries, in addition to depressive and anxiety symptoms, may influence maternal-fetal bonding during the pandemic. This work has several clinical implications. OB/GYN providers should plan to screen all pregnant women for depression, early and often, regardless of mental health history and to speak to their patients regarding their mood [62]. Clinicians should be aware that patients with higher levels of current depressive symptoms during the COVID-19 pandemic are at risk for poorer maternal-fetal bonding, which may have implications for the subsequent maternal-infant relationship and infant neurodevelopmental outcomes. At present, the anxiety symptoms reported as well as worries specific to COVID-19 by pregnant women do not appear to be a risk for maternal-fetal bonding. Resilience may improve maternal-fetal bonding even among those with higher levels of depressive symptoms and thus provides a potential target for interventions. Finally, women who are concerned about their ability to bond with their unborn baby or that their anxiety symptoms may affect bonding may benefit from reassurance based on this study data.

\begin{abstract}
Abbreviations
COVID-19: Coronavirus Disease 2019; CRISIS: Coronavirus Health Impact Survey; CD-RISC 10: Connor-Davidson Resilience Scale 10 Items; DTS: Distress Tolerance Scale; CES-D: Center for Epidemiologic Studies-Depression; GAD-7 Generalized Anxiety Disorder Scale; MAAS: Maternal Antenatal Attachment Scale; GA: Gestational Age; CBT: Cognitive-Behavioral Therapy.
\end{abstract}

\section{Acknowledgements}

The authors wish to thank Ga Tin Finneas Wong for his assistance with manuscript preparation as well as the participants who take part in this study.

\section{Authors' contributions}

A.K. conceptualized the research question, analyzed the data, and wrote the manuscript. L.M. and C.E. assisted with the interpretation of findings and editing of the manuscript. C.H.L. helped to interpret the analysis and contributed to the writing of the manuscript. All authors have read and approved the manuscript.

\section{Funding}

Support for this manuscript was provided through the Mary A. Tynan Faculty Fellowship, the Weinberg and Barton Families, Family Health and Resiliency Research Fund, and a NIH K23 MH 107714-01 A1 award (to C.H.L.). The funders provided the means for the researchers to conduct this research and played no direct role in the analysis or interpretation of this study.

\section{Availability of data and materials}

The dataset used and/or analyzed during the current study are available from the corresponding author on reasonable request.

\section{Declarations}

\section{Ethics approval and consent to participate}

All study components were approved by the Institutional Review Board at Mass General Brigham. Participants provided written consent to participation prior to the data collection, according to regulations set by the Mass General Brigham Institutional Review Board.

\section{Consent for publication}

Not applicable.

\section{Competing interests}

The authors have no disclosures to declare.

\section{Author details}

${ }^{1}$ Department of Psychiatry, Brigham and Women's Hospital, Boston, MA, USA ${ }^{2}$ Harvard Medical School, Boston, MA, USA. ${ }^{3}$ Department of Newborn Medicine, Brigham and Women's Hospital, Boston, MA, USA.

Received: 3 July 2021 Accepted: 15 November 2021

Published online: 28 December 2021

\section{References}

1. Trump DJ. Declaring a National Emergency Concerning the novel coronavirus disease (COVID-19) outbreak [internet]. Executive Office of the President; 2020. Available from: https://trumpwhitehouse.archives.gov/ presidential-actions/proclamation-declaring-national-emergency-conce rning-novel-coronavirus-disease-covid-19-outbreak/

2. Ryan GA, Purandare NC, McAuliffe FM, Hod M, Purandare CN. Clinical update on COVID-19 in pregnancy: a review article. J Obstet Gynaecol Res. 2020;46(8):1235-45.

3. Trippella G, Ciarcià M, Ferrari M, Buzzatti C, Maccora I, Azzari C, et al. COVID-19 in pregnant women and neonates: a systematic review of the literature with quality assessment of the studies. Pathogens. 2020;9(6):485. 
4. Yan J, Guo J, Fan C, Juan J, Yu X, Li J, et al. Coronavirus disease 2019 in pregnant women: a report based on 116 cases. Am J Obstet Gynecol. 2020;223(1):111-e1.

5. Panagiotakopoulos L, Myers TR, Gee J, Lipkind HS, Kharbanda EO, Ryan DS, et al. SARS-CoV-2 infection among hospitalized pregnant women: reasons for admission and pregnancy characteristics - eight US health care centers, march 1-may 30, 2020. Morb Mortal Wkly Rep. 2020;69(38):1355.

6. Liu CH, Goyal D, Mittal L, Erdei C. Patient Satisfaction with VirtualBased Prenatal Care: Implications after the COVID-19 Pandemic. Matern Child Health J. 2021;25:1735-43. https://doi.org/10.1007/ s10995-021-03211-6.

7. Leonhardt M.51.7 million parents have lost income during the coronavirus pandemic - and experts say it may be especially hard for them to head back to work [Internet]. CNBC. 2020 [cited 2021 Sep 29]. Available from: https://www.cnbc.com/2020/05/29/51-million-parents-havelost-income-during-the-coronavirus-pandemic.html

8. Liu CH, Smiley PA, Vicman JM, Wong GTF, Doan SN. The roles of life stress and preventive health behaviors on parent mental health during the COVID-19 pandemic. J Health Psychol. 2021. https://doi.org/ $10.1177 / 13591053211026742$.

9. Liu CH, Doan SN. Psychosocial Stress Contagion in Children and Families During the COVID-19 Pandemic. Clin Pediatr. 2020;59(9-10):853-5. https://doi.org/10.1177/0009922820927044.

10. Liu CH, Erdei C, Mittal L. Risk factors for depression, anxiety, and PTSD symptoms in perinatal women during the COVID-19 pandemic. Psychiatry Res. 2020;295:113552.

11. Liu CH, Tronick E. Re-conceptualising prenatal life stressors in predicting postpartum depression: cumulative-, specific-, and domain-specific approaches to calculating risk. Paediatr Perinat Epidemiol. 2013;27(5):481-90.

12. Liu CH, Phan J, Yasui M, Doan S. Prenatal life events, maternal employment, and postpartum depression across a diverse population in new York City. Community Ment Health J. 2018;54(4):410-9.

13. Mayopoulos GA, Ein-Dor T, Dishy GA, Nandru R, Chan SJ, Hanley LE, et al. COVID-19 is associated with traumatic childbirth and subsequent mother-infant bonding problems. J Affect Disord. 2021;282:122-5.

14. Layton H, Owais S, Savoy CD, Lieshout RJV. Depression, anxiety, and mother-infant bonding in women seeking treatment for postpartum depression before and during the COVID-19 pandemic. J Clin Psychiatry. 2021;82(4):0.

15. Kornfield SL, White LK, Waller R, Njoroge W, Barzilay R, Chaiyachati $\mathrm{BH}$, et al. Risk and resilience factors influencing postpartum depression and mother-infant bonding during COVID-19. Health Aff. 2021:40(10):1566-74.

16. Liu CH, Hyun S, Mittal L, Erdei C. Psychological risks to mother-infant bonding during the COVID-19 pandemic. Pediatr Res. 2021 Oct;14:1-9.

17. Schaal NK, Hagenbeck C, Helbig M, Wulff V, Märthesheimer S, Fehm T, et al. The influence of being pregnant during the COVID-19 pandemic on birth expectations and antenatal bonding. Journal of Reproductive and Infant Psychology. 2021;0(0):1-11.

18. Cranley MS. Development of a tool for the measurement of maternal attachment during pregnancy. Nurs Res. 1981;30(5):281-4. https://doi. org/10.1097/00006199-198109000-00008.

19. Göbel A, Stuhrmann LY, Harder S, Schulte-Markwort M, Mudra S. The association between maternal-fetal bonding and prenatal anxiety: an explanatory analysis and systematic review. J Affect Disord. 2018;239:313-27.

20. Ji E-K, Pretorius DH, Newton R, Uyan K, Hull AD, Hollenbach K, et al. Effects of ultrasound on maternal-fetal bonding: a comparison of two-and three-dimensional imaging. Ultrasound Obstetrics Gynecol. 2005;25(5):473-7.

21. Chudleigh T. Scanning for pleasure. Ultrasound Obstet Gynecol. 1999:14:369-71.

22. Alhusen JL, Gross D, Hayat MJ, Woods AB, Sharps PW. The influence of maternal-fetal attachment and health practices on neonatal outcomes in low-income, urban women. Research in nursing \& health. 2012;35(2):112-20.

23. Rossen L, Hutchinson D, Wilson J, Burns L, Allsop S, Elliott EJ, et al. Maternal bonding through pregnancy and postnatal: findings from an Australian longitudinal study. Am J Perinatol. 2017;34(08):808-17.

24. de Cock ES, Henrichs J, Vreeswijk CM, Maas AJ, Rijk CH, van Bakel HJ. Continuous feelings of love? The parental bond from pregnancy to toddlerhood. J Fam Psychol. 2016;30(1):125.
25. Dubber S, Reck C, Müller M, Gawlik S. Postpartum bonding: the role of perinatal depression, anxiety and maternal-fetal bonding during pregnancy. Arch Womens Ment Health. 2015 Apr;18(2):187-95.

26. Vafai Y, Steinberg JR, Shenassa ED. Maternal postpartum depressive symptoms and infant externalizing and internalizing behaviors. Infant Behav Dev. 2016:42:119-27.

27. Slomian J, Honvo G, Emonts $P$, Reginster J-Y, Bruyère O. Consequences of maternal postpartum depression: a systematic review of maternal and infant outcomes. Women's Health (Lond Engl). 2019;15:1745506519844044.

28. Giallo R, Woolhouse H, Gartland D, Hiscock H, Brown S. The emotionalbehavioural functioning of children exposed to maternal depressive symptoms across pregnancy and early childhood: a prospective Australian pregnancy cohort study. Eur Child Adolesc Psychiatry. 2015;24(10):1233-44.

29. Fransson E, Sörensen F, Kallak TK, Ramklint M, Eckerdal P, Heimgärtner M, et al. Maternal perinatal depressive symptoms trajectories and impact on toddler behavior-the importance of symptom duration and maternal bonding. J Affect Disord. 2020;273:542-51.

30. Cannella BL. Maternal-fetal attachment: an integrative review. J Adv Nurs. 2005;50(1):60-8.

31. de Jong-Pleij EAP, Ribbert LSM, Pistorius LR, Tromp E, Mulder EJH, Bilardo CM. Three-dimensional ultrasound and maternal bonding, a third trimester study and a review. Prenat Diagn. 2013;33(1):81-8

32. Cuijlits I, van de Wetering AP, Endendijk JJ, van Baar AL, Potharst ES, Pop VJM. Risk and protective factors for pre-and postnatal bonding. Infant Ment Health J. 2019;40(6):768-85.

33. Røhder K, Væver MS, Aarestrup AK, Jacobsen RK, Smith-Nielsen J, Schiøtz ML. Maternal-fetal bonding among pregnant women at psychosocial risk: the roles of adult attachment style, prenatal parental reflective functioning, and depressive symptoms. PLoS One. 2020;15(9):e0239208.

34. Yarcheski A, Mahon NE, Yarcheski TJ, Hanks MM, Cannella BL. A metaanalytic study of predictors of maternal-fetal attachment. Int J Nurs Stud. 2009;46(5):708-15.

35. Barzilay R, Moore TM, Greenberg DM, DiDomenico GE, Brown LA, White LK, et al. Resilience, COVID-19-related stress, anxiety and depression during the pandemic in a large population enriched for healthcare providers. Transl Psychiatry. 2020;10(1):1-8.

36. Grossman ES, Hoffman YS, Palgi Y, Shrira A. COVID-19 related loneliness and sleep problems in older adults: worries and resilience as potential moderators. Personal Individ Differ. 2021;168:110371.

37. Ye Z, Yang X, Zeng C, Wang Y, Shen Z, Li X, et al. Resilience, social support, and coping as mediators between COVID-19-related stressful experiences and acute stress disorder among college students in China. Applied Psychology: Health and Well-Being. 2020;12(4):1074-94.

38. McNamara J, Townsend ML, Herbert JS. A systemic review of maternal wellbeing and its relationship with maternal fetal attachment and early postpartum bonding. PLoS One. 2019;14(7):e0220032.

39. Farrell T, Reagu S, Mohan S, Elmidany R, Qaddoura F, Ahmed EE, et al. The impact of the COVID-19 pandemic on the perinatal mental health of women. J Perinat Med. 2020;48(9):971-6.

40. O'Dea S. US smartphone ownership by gender 2021 [internet]. Statista. 2021 [cited 2021 Sep 29]. Available from: https://www.statista.com/stati stics/194998/percentage-of-us-smartphone-owners-by-gender/

41. Perrin A. Mobile technology and home broadband 2021 [internet]. Washington, DC: Pew Research Center; 2021 Jun [cited 2021 Sep 29]. (Internet \&Technology). Available from: https://www.pewresearch.org/internet/ 2021/06/03/mobile-technology-and-home-broadband-2021/

42. Nikolaidis A, Paksarian D, Alexander L, Derosa J, Dunn J, Nielson DM, et al. The coronavirus health and impact survey (CRISIS) reveals reproducible correlates of pandemic-related mood states across the Atlantic. Sci Rep. 2021;11(1):8139.

43. Liu CH, Zhang E, Wong GTF, Hyun S. Factors associated with depression, anxiety, and PTSD symptomatology during the COVID-19 pandemic: clinical implications for US young adult mental health. Psychiatry Res. 2020;290:113172.

44. Campbell-Sills L, Stein MB. Psychometric analysis and refinement of the connor-Davidson resilience scale (CD-RISC): validation of a 10-item measure of resilience. J Traum Stress. 2007;20(6):1019-28.

45. Simons JS, Gaher RM. The distress tolerance scale: development and validation of a self-report measure. Motiv Emot. 2005;29(2):83-102. 
46. Shulman HB, D'Angelo DV, Harrison L, Smith RA, Warner L. The pregnancy risk assessment monitoring system (PRAMS): overview of design and methodology. Am J Public Health. 2018;108(10):1305-13.

47. Radloff LS. The CES-D scale: a self-report depression scale for research in the general population. Appl Psychol Meas. 1977;1 (3):385-401.

48. Spitzer RL, Kroenke K, Williams JB, Löwe B. A brief measure for assessing generalized anxiety disorder: the GAD-7. Arch Intern Med. 2006;166(10):1092-7.

49. Condon JT. The assessment of antenatal emotional attachment: development of a questionnaire instrument. Br J Med Psychol. 1993;66(2):167-83.

50. Lewinsohn PM, Seeley JR, Roberts RE, Allen NB. Center for Epidemiologic Studies Depression Scale (CES-D) as a screening instrument for depression among community-residing older adults. Psychol Aging. 1997;12(2):277-87.

51. Martin JA, Hamilton BE, Osterman MJK, Driscoll AK, Division of Vital Statistics. Births: Final Data for 2019. Hyattsville, MD: National Center for Health Statistics; 2021 p. 51. (National Vital Statistics Reports, Volume 70). Report No.: 2 .

52. Snider S. Where do I fall in the American economic class system? [internet]. U.S. news Money. 2020 [cited 2021 Sep 29]. Available from: https:// money.usnews.com/money/personal-finance/family-finance/articles/ where-do-i-fall-in-the-american-economic-class-system

53. Ertmann RK, Bang CW, Kriegbaum M, Væver MS, Kragstrup J, Siersma V, et al. What factors are most important for the development of the maternal-fetal relationship? A prospective study among pregnant women in Danish general practice. BMC Psychol. 2021;9(1):1-9.

54. Wyckoff AS. AAP issues guidance on breastfeeding during COVID-19 pandemic [Internet]. AAP News. 2021. [cited 2021 Sep 29]. Available from: https://publications.aap.org/aapnews/news/6712.

55. Edhborg M, Nasreen H-E, Kabir ZN. Impact of postpartum depressive and anxiety symptoms on mothers' emotional tie to their infants $2-3$ months postpartum: a population-based study from rural Bangladesh. Arch Womens Ment Health. 2011;14(4):307-16.

56. Ma X, Wang $Y, H u H$, Tao XG, Zhang $Y$, Shi $H$. The impact of resilience on prenatal anxiety and depression among pregnant women in Shanghai. J Affect Disord. 2019;250:57-64.

57. Gur RE, White LK, Waller R, Barzilay R, Moore TM, Kornfield S, et al. The disproportionate burden of the COVID-19 pandemic among pregnant black women. Psychiatry Res. 2020;293:113475.

58. Joyce S, Shand F, Tighe J, Laurent SJ, Bryant RA, Harvey SB. Road to resilience: a systematic review and meta-analysis of resilience training programmes and interventions. BMJ Open. 2018:8(6):e017858.

59. Robertson IT, Cooper CL, Sarkar M, Curran T. Resilience training in the workplace from 2003 to 2014: a systematic review. J Occup Organ Psychol. 2015;88(3):533-62.

60. Victor PP, Teismann T, Willutzki U. A pilot evaluation of a strengths-based CBT intervention module with college students. Behav Cogn Psychother. 2017:45(4):427-31.

61. Fairbrother N, Young AH, Janssen P, Antony MM, Tucker E. Depression and anxiety during the perinatal period. BMC Psychiatry. 2015;15(1):206.

62. Liu CH, Tronick E. Do patient characteristics, prenatal care setting, and method of payment matter when it comes to provider-patient conversations on perinatal mood? Matern Child Health J. 2012;16(5):1102-12.

\section{Publisher's Note}

Springer Nature remains neutral with regard to jurisdictional claims in published maps and institutional affiliations.

Ready to submit your research? Choose BMC and benefit from:

- fast, convenient online submission

- thorough peer review by experienced researchers in your field

- rapid publication on acceptance

- support for research data, including large and complex data types

- gold Open Access which fosters wider collaboration and increased citations

- maximum visibility for your research: over $100 \mathrm{M}$ website views per year

At BMC, research is always in progress.

Learn more biomedcentral.com/submissions 